\title{
Effects of aerosols on the surface solar radiation in a tropical urban area
}

\author{
Ming-Dah Chou, Po-Hsiung Lin, Po-Lun $\mathrm{Ma}^{1}$ \\ Department of Atmospheric Sciences \\ National Taiwan University \\ Taipei, Taiwan \\ Ho-Jiunn Lin \\ Research Center for Environmental Changes \\ Academia Sinica \\ Taipei, Taiwan
}

\begin{abstract}
Surface radiation measurements at an urban site in southern Taiwan during the dry winter season, December 2003-March 2004, are used to investigate the aerosol properties and the effects of aerosols on the surface solar radiation in clear skies. The AERONET-retrieved monthly mean aerosol optical thickness at $0.5 \mu \mathrm{m}$ ranges from 0.52 to 1.18 with a mean of 0.73 for the four winter months. The single-scattering albedo and asymmetry factor remain nearly constant with a mean of $\sim 0.95$ for the former and $\sim 0.70$ for the latter. Thus the air of Tainan during the winter is highly polluted, and the aerosols are moderately absorbing. A new approach is developed to estimate the effect of aerosols on the surface radiation from surface observations. The relationship between the surface radiation and the aerosol optical thickness is established for narrow intervals of the solar zenith angle by regression of the atmospheric path transmission against the aerosol optical path. It is found that the relationship is surprisingly linear. Based on the relationship, the effect of aerosols on the surface radiation and the sensitivity of surface radiation to the aerosol optical thickness are computed. For the four-month average, the effect of aerosols is to reduce the incident surface solar radiation by $\sim 39 \mathrm{Wm}^{-2}$, and the sensitivity of the surface radiation to aerosols is a reduction of $\sim 53 \mathrm{Wm}^{-2}$ per unit increase of aerosol optical thickness at $0.5 \mu \mathrm{m}$. These results are in good agreement with radiative transfer model calculations.
\end{abstract}

\footnotetext{
${ }^{1}$ Now a graduate student at the Department of Earth and Planetary Sciences, Johns Hopkins University, Baltimore, Maryland.
} 


\section{Introduction}

Aerosols have a short lifetime and large spatial and temporal variations, and the global distribution of aerosols can only be observed from space [Kaufman, 2004]. Satellite measurements of radiances in solar spectral channels provide information on the column-integrated aerosol optical thickness $(\tau)$, which is the most important parameter for the determination of the impact of aerosols on the solar heating of the earth-atmosphere system. However, the radiance measurements contain little information for the derivation of the aerosol single-scattering albedo $\left(\omega_{o}\right)$ and asymmetry factor $(g)$, and the estimation of the effect of aerosols on the solar heating (or aerosol radiative effect, ARE) of the earth-atmosphere system has to rely on other data sources for $\omega_{o}$ and $g$. The data on $\omega_{o}$ is particularly critical for determining the partition of the ARE between the atmosphere and the underlying surface. This partition of the ARE has an impact on the stability of the atmosphere and, hence, convection, precipitation, and circulation.

Aerosol optical properties and the aerosol impact on solar heating can also be derived from radiation measurements at the surface. The field-of-view of the surface observations is very small, and the problem of cloud contamination encountered in the satellite measurements is much alleviated when observations are conducted from the surface. The multi-channel and multi-angle radiance measurements from the surface can provide information on the absorption of solar radiation by aerosols and the aerosol particle size, which in turn can be used to estimate $\omega_{o}$ and $g$. As opposed to the observations from space, the observations from the surface are unaffected by the surface albedo. This is especially important over land where the satellite retrieval of aerosols has a large uncertainty due to the uncertainty in surface albedo. However, retrievals of aerosols from observations at the surface are limited to a small number of sites mostly in

populated regions. Observations from the surface are inadequate for providing information on regional and global distributions of aerosols. 
Reliable retrievals of aerosols from surface observations require radiance measurements in multiple viewing angles and multiple spectral channels, such as the measurements using Cimel sunphotometers of the AERONET project [Holben et al., 1998]. AERONET radiance measurements are mostly used for validating satellite retrievals of aerosols [Chu et al., 2002; Remer et al., 2005]. To reliably estimate the impact of aerosols on surface radiation, it requires co - located broadband solar radiation measurements with aerosol measurements. There are not many sites around the world with co-located aerosol and broadband solar radiation measurements, and there are only a few studies in recent years addressing the aerosol radiative effect at the surface using both sets of surface measurements. Jayaraman et al. [1998] derived the sensitivity of surface solar radiation to the aerosol optical thickness using simultaneous measurements of aerosol optical thickness, size distribution, and incoming solar radiation. The measurements were conducted in January-February 1996 during a cruise over the Arabian Sea and the Indian Ocean. They found that, when normalized by the solar zenith angle, the direct visible $(<0.78 \mu \mathrm{m})$ solar flux decreases by $\sim 42 \mathrm{Wm}^{-2}$, the diffuse sky radiation increases by $\sim 30 \mathrm{Wm}^{-2}$, and the decrease of net flux by $\sim 12 \mathrm{Wm}^{-2}$ per 0.1 increase in aerosol optical thickness at $0.5 \mu \mathrm{m}$. The information is very useful for understanding the impact of aerosol on the surface heating. Podgorny et al. [2000] validated the model-calculated surface radiation with that observed on the island of Kaashidhoo (4.97N, 73.47E). Aerosol chemical, microphysical, and optical properties, as well as radiative fluxes were measured during February and March of 1998 as part of the first phase of the INDOEX [Ramanathan et al., 1996] field experiment. Based on the aerosol optical thickness retrieved from surface radiation measurements and the radiative transfer model calculations, they found that aerosols over tropical Indian Ocean have a large impact on the clear-sky radiation budget of the atmosphere and the surface.

In this study, we investigate the impact of aerosols on the surface radiation using 
simultaneous measurements of aerosol optical properties and surface radiation in the city of Tainan on the southwest coast of Taiwan. Because of the nonlinearity between radiative transfer and the optical path, we also examine in detail the sensitivity of the surface radiation to $\tau$ as a function of the solar zenith angle. The monthly mean sensitivity of the surface flux to $\tau$ and the impact of aerosols on the surface radiation are then calculated. Finally, the results derived from measurements are compared with the calculations using a radiative transfer model.

\section{Surface Observations}

To investigate processes of the production and transport of ozone and aerosols in Taiwan, the Research Center for Environmental Changes (RCEC), Academia Sinica, has conducted a set of radiation measurements at the regional weather station of the Taiwanese Central Weather Bureau in the city of Tainan $\left(120.2^{\circ} \mathrm{E}, 23.0^{\circ} \mathrm{N}\right)$ located on the southwest cost of Taiwan. The measurements include the total solar flux $(0.296 \mu \mathrm{m}-3.0$ $\mu \mathrm{m})$ using Eppley Precision Spectral Pyranometers (PSP) and the radiances in seven spectral channels ranging from $0.34 \mu \mathrm{m}$ to $1.02 \mu \mathrm{m}$ using Cimel sunphotometers. The PSP samples data in one second and are subsequently averaged to 1-min resolution. The data are archived and processed at RCEC. Calibration of the PSP involves darkroom calibration and outdoor intercomparison. The Cimel measures the direct solar radiation at a 15-min resolution and the sky radiation at a $1-\mathrm{hr}$ resolution. As part of the AERONET project, data measured by the Cimel are sent to US NASA/Goddard Space Flight Center for the retrievals of aerosol optical thickness, single - scattering albedo, and asymmetry factor. When the sky is clear (cloud-free), the aerosol optical thickness is retrieved at a resolution of 15-min, and the single-scattering albedo and asymmetry factor are retrieved at a resolution of 1-hr. Both PSP and Cimel are calibrated during the summer, and the measurements are conducted only in the winter half of the year (November-April). Daily 
maintenance of the instruments includes cleaning of the glass dome of the pyranometer, checking of the sun-tracking of the Cimel, and checking of the data auto - downloading system. The data used in this study cover four months from December 2003 to March 2004.

The city of Tainan has a population of $\sim 750,000$. It is located within the East Asian monsoon regime. During the winter, East Asia is dominated by the high pressure system centered in northern China and Mongolia. The prevailing winds of Taiwan in the winter are northeasterly. With the high Central Mountain Range (height $>3 \mathrm{~km}$ ) located to the east, Tainan is dry and relatively clear during the winter. During the summer, the climate of southern Taiwan is controlled by the southwesterly flow from the South China Sea. It is humid and cloudy. The annual mean precipitation during $2002-2004$ is $1,073 \mathrm{~mm}$, but the winter four-months of the year (October-March) gets only $83 \mathrm{~mm}$. Thus, the weather conditions during the winter are most favorable for retrieving aerosol optical properties from Cimel radiance measurements.

The Cimel measures radiances at seven channels ranging from $0.34 \mu \mathrm{m}$ to $1.02 \mu \mathrm{m}$. The aerosol optical thickness is retrieved at all seven channels, but the single-scattering albedo and asymmetry factor are retrieved only at four channels (see Table 1). Because of the presence of clouds, aerosol retrievals are incomplete over any given day. Therefore, it is not feasible to derive diurnal variation of the aerosol radiative effect. Instead, we use daily mean values of aerosol optical properties to derive the daily mean solar radiation. To ensure we have representative daily mean values of aerosols, the daily mean values of $\tau, \omega_{o}$, and $g$ are computed only for those days when there are at least 2 AERONET aerosol retrievals of all the three parameters. Table 2 shows the mean $\tau, \omega_{0}, g$, as well as the range of these parameters within the individual months of December 2003 - March 2004. The air of Tainan in the winter is highly polluted. The monthly mean aerosol optical thickness at $0.5 \mu \mathrm{m}$ increases from 0.52 in December 2003 to 1.18 in March 2004 
with a mean of 0.73 for the four winter months. The monthly mean single-scattering albedo and asymmetry factor remain nearly constant at $\sim 0.95$ and $\sim 0.70$, respectively. Thus, the aerosols are moderately absorbing. The range within individual months is large for $\tau$ but is small for $\omega_{0}$ and $g$.

The surface radiation measured by the PSP, $F_{o b s}$ total, during the four months is shown in Table 3. The incoming solar radiation at the top of the atmosphere and the atmospheric transmission function are also shown in the table. The former is calculated as a function of the Julian day and the latitude of Tainan, whereas the latter is simple the ratio of the surface radiation to the incoming solar radiation at the top of the atmosphere. For the four months, the solar radiation incident at the surface is half of the insolation at the top of the atmosphere, and the mean atmospheric transmission is 0.5 . The $50 \%$ extinction of the solar radiation is due to the absorption and scattering by aerosols, clouds, and atmospheric gases, such as water vapor and ozone. If we assume the surface albedo is 0.2 , then the surface absorbs about $40 \%$ of the incoming solar radiation at the top of the atmosphere.

\section{Radiative Transfer Model Calculations}

The aerosol radiative effect is also investigated with calculations using the radiative transfer model of Chou and Lee [1996] and Chou and Suarez [1999]. The model includes the absorption by ozone, water vapor, oxygen and $\mathrm{CO}_{2}$, as well as the absorption and scattering by clouds, aerosols, and molecules (Rayleigh scattering). Fluxes are integrated virtually over the entire spectrum, from $0.175 \mu \mathrm{m}$ to $10 \mu \mathrm{m}$. Depending upon the nature of absorption, different approaches are applied to different absorbers. In the ultraviolet and photosynthetically active region (wavelength $<0.7 \mu \mathrm{m}$ ), the spectrum is divided into 5 bands (see Table 1), and single $\mathrm{O}_{3}$ absorption coefficient and Rayleigh scattering coefficient are used for each band. In the infrared (wavelength $>0.7 \mu \mathrm{m}$ ), the spectrum is 
divided into 3 bands, and the $\mathrm{k}$-distribution method for water vapor absorption is applied. Reflection and transmission of a cloud and aerosol - laden layer are computed using the $\delta$-Eddington approximation. A special feature of this model is that absorption due to a number of minor absorption bands is included. Individually the absorption in those minor bands is small, but collectively the effect is large, $\sim 10 \%$ of the atmospheric heating.

There are no atmospheric soundings at the Tainan site, but at the Central Weather Bureau's Ping-Dong station $60 \mathrm{~km}$ south of Tainan there are radiosondings twice a day at 6:00 am and 6:00 pm LT. Ping-Dong and Tainan are in the same climatic regime that has a dry winter and a wet summer. We use monthly mean temperature and humidity profiles measured at Ping-Dong as input data to the radiative transfer model for computing the daily mean solar radiation in Tainan. Although water vapor is the most important atmospheric constituent in the absorption of solar radiation, Chou and Zhao [1997] has shown that the absorption of solar radiation is not overly sensitive to the variation of water vapor. A change of column water vapor from 3.0 to $4.0 \mathrm{~g} \mathrm{~cm}^{-2}$, for example, reduces the surface solar heating by only $\sim 8 \mathrm{Wm}^{-2}$ for a solar zenith angle, $\theta_{o}$, of $60^{\circ}$. On a daily-mean basis, this number is roughly reduced to half. The surface solar radiation is even less sensitive to the column ozone amount. A change of the column ozone amount from 0.25 to $0.35(\mathrm{~cm}-\mathrm{atm})_{\text {stp }}$ reduces the surface solar heating by $\sim 2.0 \mathrm{Wm}^{-2}$ for $\theta_{o}=60^{\circ}$. Therefore, we use a single value of $0.3(\mathrm{~cm} \text {-atm })_{\text {stp }}$ for the column ozone amount in the computation of solar radiation. These approximations for temperature, humidity, and ozone amounts should have little impact on the results of the study on the aerosol radiative effect.

The seven channels of the Cimel are located within Bands 4-6 of the radiative transfer model (Table 1). The aerosol optical properties of a model band are derived by averaging the AERONET-retrieved aerosol optical properties within the band. For those 
model bands outside the Cimel channels, the aerosol optical properties are set equal to that of the nearest Cimel channels. The AERONET aerosol retrievals do not provide information on the vertical distribution. We assume that aerosols are confined to and uniformly distributed below the $750-\mathrm{hPa}$ level, which is equivalent to a height of $\sim 2 \mathrm{~km}$. Since the aerosols are only moderately absorbing, the assumption does not have any significant impact on the surface radiation calculations. When we change the top of aerosol layer from $750 \mathrm{hPa}$ to $600 \mathrm{hPa}(\sim 4 \mathrm{~km})$ and repeat the calculations for the cases of Tainan during December 2003-March 2004, the reflection of solar radiation to the space increases slightly but the absorption of solar radiation in the atmosphere decreases slightly. As a result, the surface solar fluxes are nearly identical for both sets of calculations.

Since there are no atmospheric soundings at the Tainan site, we use the monthly mean temperature and humidity profiles observed at Ping-Dong in the solar radiation calculations using the radiation model. As mentioned above, observations of aerosol diurnal variation is not possible due to the presence of clouds. We use daily mean aerosol optical properties in the model calculations of solar radiation. Hence, the variation of solar radiation from day to day is due to changes in the extraterrestrial solar flux, $S_{0}$, the length of daytime, and the aerosols. The solar radiation is calculated only for those days when there are Cimel-retrieved daily mean aerosol properties. The first two columns of Table 4 shows the model-calculated downward solar radiation at the surface without aerosols $\left(F_{\text {mod }}{ }^{N A}\right)$ and with aerosols $\left(F_{\text {mod }}{ }^{W A}\right)$, which are $\sim 76 \%$ and $64 \%$ of the incoming solar radiation at the top of the atmosphere, $\overline{\mu_{o} S_{o}}$, as shown in Table 3 . It is noticed that the surface observations do not provide any information on the cloud amount and cloud optical properties. Solar radiation is only calculated for clear, cloud-free skies. 


\section{Atmospheric Path Transmission and Aerosol Optical Path}

To estimate the aerosol radiative effect from surface observations, we need to know the relationship between the surface radiation and the aerosol optical depth. This relationship is a function of the extraterrestrial solar radiation, $S_{o}$, and the solar zenith angle, $\theta_{o}$. For a given $S_{o}$, the surface radiation is smaller for a larger $\theta_{o}$. For a given $\theta_{o}$, on the other hand, the surface radiation is larger for a larger $S_{o}$. When the surface radiation is normalized by the incoming solar radiation at the top of the atmosphere, data from different months can be put together for deriving the relationship between the surface radiation and the aerosol optical thickness. In essence, the normalized surface radiation is the atmospheric path transmission given by

$$
T=F_{o b s} /\left(\mu_{o} S_{o}\right)
$$

where $F_{o b s}$ is the observed surface radiation, and $\mu_{o}$ is the cosine of the solar zenith angle.

The AERONET retrieval algorithm identifies skies which are free of clouds and retrieves the aerosol optical thickness, single-scattering albedo, and asymmetry factor using the Cimel radiation measurements. When the sky is identified as cloud-free, we group surface radiation and the aerosol optical thickness into $\theta_{o}-$ bins with an interval of

$10^{\circ}$, and the atmospheric path transmission is plotted against the aerosol optical path $\left(\tau / \mu_{o}\right)$, where $\tau$ is the aerosol optical thickness. Figures $1 \mathrm{a}-1 \mathrm{e}$ show the scatterplots of the individual $\theta_{o}$-bins. Each point in the plots represents 1-min mean PSP-measured atmospheric path transmission and the instantaneous AERONET-retrieved aerosol optical path during the 4-month period from December 2003 to March 2004. The straight lines given by the following equation are the least - square - error fit to the data,

$$
T=\alpha+\gamma \tau / \mu_{o}
$$


Here $\tau$ is the aerosol optical thickness at $0.5 \mu \mathrm{m}$, and $\alpha$ and $\gamma$ are the regression coefficients. Values of $\alpha$ and $\gamma$ are listed in Table 5. In Tainan during the winter, the $\theta_{o}$ is large $\left(>23^{\circ}\right)$ even at noontime. There are only a few cases with $\theta_{o}<30^{\circ}$ when the sky is identified as clear from the Cimel radiance measurements. On the other hand, there are no aerosol retrievals for $\theta_{o}>80^{\circ}$. For these two $\theta_{o}$ - bins, the parameters $\alpha$ and $\gamma$ cannot be derived from the Cimel measurements. Instead, we approximate these parameters by extrapolation from those of neighboring $\theta_{o}$-bins. Because the length of local time is short for $\theta_{o}<30^{\circ}$ and $\mu_{o}$ is small for $\theta_{o}>80^{\circ}$, uncertainties in the extrapolation of $\alpha$ and $\gamma$ are not expected to induce any significant errors in the estimation of the daily mean radiation.

It is interesting that the atmospheric path transmission can be fit so well with a linear function of $\tau / \mu_{o}$. For the direct beam only, the extinction (or transmission) should vary exponentially with $\tau / \mu_{o}$. With an asymmetry factor of 0.7 , however, most of the radiation scattered by aerosols are directed downward toward the surface, and the total (direct + diffuse) radiation does not decrease with increasing $\tau / \mu_{o}$ nearly as fast as the direct radiation.

For a larger optical path, radiative fluxes are less sensitive to the optical path, and, hence, the magnitude of $\gamma$ decreases with increasing $\theta_{o}$. The intercept $\alpha$ approximates the atmospheric transmission with $\tau=0$, which should also decrease with increasing $\theta_{o}$ primarily due to the increase in water vapor path for a larger $\theta_{o}$. It can be seen in Table 5 that both the magnitude of the slope $\gamma$ and the intercept $\alpha$ decrease with increasing $\theta_{o}$ as expected.

In the regression, the solar radiation is normalized by the insolation at the top of the atmosphere, and the aerosol optical thickness is normalized by $\mu_{o}$. In principle, all data measured in different days and at different local times can be included in a scatterplot for the regression. With the normalization, the number of data increases, and the reliability of 
the regression also increases. However, there are problems when data measured at different $\theta_{o}$ are mixed together. In addition to the variation of water vapor optical path with $\theta_{o}$ mentioned above, there are two other reasons for the separation of the data into $\theta_{o}$-intervals. Firstly, the intercept $\alpha$ is the atmospheric path transmission without aerosols that should decrease with increasing $\theta_{o}$. With the regression applied to narrow $\theta_{o}$-intervals, the atmospheric transmission without aerosols can be more accurately estimated. Secondly, the range of the aerosol optical path, $\tau / \mu_{o}$, within a $\theta_{o}-$ bin reduces with narrower $\theta_{o}$-bins, and the regression can be made more accurately.

When all data measured at different $\theta_{o}$ are included in the same plot, the results are shown in Figure 2. The regression coefficients are $\alpha=0.660$ and $\gamma=-0.0936$. The plot is similar to Figure 9 of Jayaraman et al. [1998], except in their figure the solar flux is for the spectral band $<0.78 \mu \mathrm{m}$ and is not normalized by the extraterrestrial solar radiation, $S_{o}$. The data points in their Figure 9 are measurements conducted during a field cruise over the Arabian Sea and the Indian Ocean in January-February 1996. The slope of their linear regression is $140 \mathrm{Wm}^{-2}$. When normalized by $S_{o}$, which is $\sim 1400 \mathrm{Wm}^{-2}$ in January-February, we have $\gamma=-0.1$. It is close to the slope $\gamma=-0.0936$ of the regression shown in our Figure 2. Since the solar flux measurements used in Jayaraman et al. [1998] include only the spectral band $<0.78 \mu \mathrm{m}$, the magnitude of the slope should be larger than 0.1 if the aerosol effect of the spectral bands $>0.78 \mu \mathrm{m}$ is included. Thus, the slope of the regression is greater for the data measured over the Arabian Sea and the Indian Ocean than for the data measured in Tainan. It implies that aerosols in the Arabian Sea and the Indian Ocean are more absorptive than the aerosols in Tainan. This is consistent with the aerosols measured on the island of Kaashidhoo in the equatorial Indian Ocean during winter time [Podgorny et al., 2000]. The aerosol single-scattering albedo, $\omega_{o}$, is $0.88-0.9$ on Kaashidhoo and $\sim 0.95$ in Tainan. 


\section{Aerosol Radiative Effect (ARE) and Sensitivity (ARS)}

The situation that there are no clouds in a day is very rare in Tainan. It is nearly impossible to estimate the effect of aerosols on the clear-sky surface radiation for individual days, and composite of clear - sky surface radiation measurements at various $\theta_{o}$ is necessary for the estimation of the mean ARE over an extended period of time, such as a month or a season.

The clear-sky surface radiation at local time $t$ can be estimated from Equations (1) and (2),

$$
F(t)=S_{o} \mu_{o}(t)\left[\alpha\left(\mu_{o}\right)+\gamma\left(\mu_{o}\right) \tau(t) / \mu_{o}(t)\right]
$$

and the daily mean clear-sky surface radiation with aerosols (WA) and without aerosols (NA) can be computed from

$$
\begin{aligned}
& F_{i}^{W A}=S_{o, i} \int \mu_{o}(t)\left[\alpha\left(\mu_{o}\right)+\gamma\left(\mu_{o}\right) \overline{\tau_{i}} / \mu_{o}(t)\right] d t \\
& F_{i}^{N A}=S_{o, i} \int \mu_{o}(t) \alpha\left(\mu_{o}\right) d t
\end{aligned}
$$

where $\overline{\tau_{i}}$ is the mean aerosol optical thickness at $0.5 \mu \mathrm{m}$ of the day $i$, and the integration is over a day. It is noticed that the function $\mu_{\mathrm{o}}(t)$ changes from day to day, whereas $\alpha\left(\mu_{\mathrm{o}}\right)$ and $\gamma\left(\mu_{\mathrm{o}}\right)$ are not a function of $i$. There is only one set of $\alpha\left(\mu_{\mathrm{o}}\right)$ and $\gamma\left(\mu_{\mathrm{o}}\right)$, given in Table 5, for the entire 4-month period from December 2003 to March 2004.

Finally, the aerosol radiative effect, is computed from 


$$
A R F_{i}=F_{i}^{W A}-F_{i}^{N A}
$$

and the sensitivity of surface radiation to aerosol optical thickness, or aerosol radiative sensitivity (ARS), is given by

$$
\frac{d F^{W A}}{d \bar{\tau}}=S_{o, i} \int \gamma\left(\mu_{o}\right) d t
$$

The ARS is a function of time because not only $S_{\mathrm{o}}$ but also the length of a day changes with time. The ARS should also be dependent upon water vapor content, but the dependence is weak.

The monthly and seasonal mean clear-sky surface radiation with aerosols, $F_{o b s}{ }^{W A}$, and without aerosols, $F_{o b s}{ }^{N A}$, estimated from observations using Equations (4) and (5) are shown in Table 4. It can be seen in the table that both $F_{o b s}{ }^{N A}<F_{\text {mod }}{ }^{N A}$ and $F_{o b s}{ }^{W A}<F_{\text {mod }}{ }^{W A}$ by $\sim 20 \mathrm{Wm}^{-2}$. It is likely we have underestimated $F_{o b s}{ }^{N A}$ and $F_{o b s}{ }^{W A}$ and overestimated $F_{\text {mod }}^{N A}$ and $F_{\text {mod }}^{W A}$. By comparing model calculations and surface observations, we have found that there are cases when the former is significantly larger than the later. For those cases, the sky is most likely cloudy but is mistakenly identified by the AERONET retrieval algorithm as clear. So, the impact of clouds on the surface radiation is mistakenly treated as the impact of aerosols, and $F_{o b s}{ }^{W A}$ is underestimated. In a study on the effects of bias in solar radiative transfer codes on global climate model simulations, Arking [2005] compared the surface radiation calculated using the model of Chou and Suarez [1999] with the measurements made at the Atmospheric Radiation Measurement (ARM) program's Southern Great Plain site in Oklahoma. He found that the model-calculated surface radiation is larger than the measurements and suggested that the radiation model might have underestimated the absorption of solar radiation by water 
vapor and, hence, overestimated $F_{\text {mod }}{ }^{N A}$.

The ARE estimated from surface observations and computed from model calculations are shown in Table 6. It is computed from Equation (6) with $F^{N A}$ and $F^{W A}$ taken from Table 4. The agreement between the two different assessments of ARE is very good. The potential problem of the radiation model concerning the absorption of solar radiation by water vapor, as mentioned above, does not seem to have any significant impact on the calculation of ARE because both $F_{\text {mod }}{ }^{W A}$ and $F_{\text {mod }}{ }^{N A}$ are calculated using the same parameterization for water vapor absorption. Errors in $F_{\text {mod }}{ }^{W A}$ and $F_{\text {mod }}{ }^{N A}$ arising from the parameterization for the absorption due to water vapor tend to cancel out when taking the difference to derive the ARE.

Table 6 also shows the ARS estimated from surface observations and computed using a radiation model. The former is computed using Equation (7) whereas the latter is computed as the ratio of the ARE to the aerosol optical thickness $\tau$ given in Table 2 . It can be seen that the two estimates of ARS are in good agreement. For the four-month mean, the ARS is practically identical between surface observations and model calculations. For individual months, the difference is $\leq 10 \%$. The four-month mean ARS of $-51 \mathrm{Wm}^{-2}$ in Tainan is weaker than $-82 \mathrm{Wm}^{-2}$ on the equatorial island of Kaashidhoo as estimated by Podgorny et al. [2000]. The difference is primarily due to a stronger absorption by aerosols on Kaashidhoo than in Tainan. The single-scattering albedo, $\omega_{o}$, is $0.88-0.9$ for the former and 0.95 for the latter. The difference in the incoming solar radiation at the top of the atmosphere, $\overline{\mu_{o} S_{o}}$, also contributes slightly to the difference in ARS. The $\overline{\mu_{o} S_{o}}$ is $345 \mathrm{Wm}^{-2}$ during February-March on Kaashidhoo and is $322 \mathrm{Wm}^{-2}$ during November-March in Tainan. The former is $7 \%$ larger than the latter.

When the coefficients $\alpha(=0.66)$ and $\gamma(=-0.0936)$ are taken from the regression that includes data measured at all $\theta_{o}$, the estimated ARE and ARS are shown in Table 7. 
Compared to the ARE and ARS shown in Table 6, both the ARE and ARS using the regression that includes data of all $\theta_{o}$ are significantly overestimated by $\sim 7-10 \mathrm{Wm}^{-2}$.

\section{Conclusions}

Aerosols in clear skies have an impact on the surface heating by primarily reflecting and secondarily absorbing the solar radiation. The impact is especially large in urban areas where the air is highly polluted. Since 2003 there have been simultaneous measurements of the surface solar radiation and aerosols in the city of Tainan on the southwest coast of Taiwan. The measurements are conducted only during the dry winter season, when it is less cloudy and favorable for aerosol retrievals. The instruments are well calibrated during the wet summer season and well maintained on a daily basis during the winter season when measurements are conducted. Data from four months (December 2003-March 2004) of measurements are used to study the effect of aerosols on the surface solar heating and the sensitivity of surface solar radiation to aerosols. The aerosol radiative effect and sensitivity are also computed using a radiative transfer model, and the results are compared with that derived from surface observations.

A new approach is developed to estimate the effect of aerosols on the surface radiation from surface observations. The relationship between the atmospheric path transmission and the aerosol optical path is derived by normalizing the incident surface radiation by the incoming solar radiation at the top of the atmosphere, $\mu_{o} S_{o}$, and aerosol optical thickness by the cosine of the solar zenith angle, $\mu_{o}$. It is found that the relationship between the atmospheric path transmission and the aerosol optical path is surprisingly linear. The intercept and the slope of the regression lines represent, respectively, the atmospheric transmission free of aerosols and the sensitivity of surface radiation to aerosols. Because the atmospheric water vapor path and the aerosol optical path increase with increasing solar zenith angle, $\theta_{0}$, both the coefficients of the regression 
decrease with increasing $\theta_{\mathrm{o}}$. Therefore, the regression is applied to narrow $\theta_{\mathrm{o}}$-intervals.

Applying the daily mean optical thickness retrieved from the Cimel radiance measurements to the relationship between the atmospheric path transmission and the aerosol optical path, the effect of aerosols on the surface radiation and the sensitivity of surface radiation to the variation of aerosol optical thickness are computed. It is found that, for the four-month average, the effect of aerosols is to reduce the incident surface solar radiation by $\sim 39 \mathrm{Wm}^{-2}$, and the sensitivity of the surface radiation to aerosols is a reduction of $\sim 51 \mathrm{Wm}^{-2}$ per unit increase of aerosol optical thickness at $0.5 \mu \mathrm{m}$. These results are in good agreement with radiative transfer model calculations using the surface-based observations of temperature, humidity, and aerosol optical properties.

The AERONET-retrieved monthly mean aerosol optical thickness at $0.5 \mu \mathrm{m}$ measured in Tainan ranges from 0.52 to 1.18 with a mean of 0.73 for the four months December 2003-march 2004. The single-scattering albedo and asymmetry factor remain nearly constant for the four months with a mean of $\sim 0.95$ for the former and $\sim 0.70$ for the latter. Thus, the air of Tainan during the winter is highly polluted, and the aerosols are moderately absorbing.

Acknowledgment. This research was supported by the National Science Council, Taiwan. 


\section{References}

Arking, A. (2005), Effects of bias in solar radiative transfer codes on global climate model simulations, Geophys. Res. Lett., 32, L20717, doi: 10.1029/2005GL023644.

Chou, M.-D., and W. T. Lee (1996), Parameterizations for the absorption of solar radiation by water vapor and ozone, J. Atmos. Sci., 53, 1203-1208.

Chou, M.-D., and W. Zhao (1997), Estimation and model validation of surface solar radiation and cloud radiative forcing using TOGA COARE measurements, $J$. Climate, 4, 610-620.

Chou, M.-D., and M. J. Suarez (1999), A solar radiation parameterization for atmospheric studies, NASA Tech. Memo. 104606, 15, 40 pp.

Chu, D. A., Y. J. Kaufman, C. Ichoku, L. A. Remer, D, Tanre, B. N. Holben (2002), Validation of MODIS aerosol optical depth retrieval over land, Geophys. Res. Lett., 29(12), doi:10.1029/2001GL013205.

Holben, B. N., T. F. Eck, I. Slutsker, D. Tanre, J. P. Buis, A. Setzer, E Vermote, J. A. Reagan, Y. J. Kaufman, T. Nakajima, F. Lavenu, I. Jankowiak, and A. Smirnov (1998), AERONET - A federated instrument network and data archive for aerosol characterization, Remote Sens. Environ., 66, 1-16.

Jayaraman, A., D. Lubin, S. Ramachandran, V. Ramanathan, E. Woodbridge, W. Collins, and K. S. Zalpuri (1998), Direct observations of aerosol radiative forcing over the tropical Indian Ocean during the Jan - Feb 1996 pre-INDOEX cruise, J. Geophys. Res. 103, $13,827-13,836$.

Kaufman, Y. J., T. Didier, and O. Boucher (2002), A satellite view of aerosols in the climate system, Nature, 419, 215-223.

Podgorny, I. A., W. Conant, V. Ramanathan, K. Satheesh (2000), Aerosol modulation of atmospheric and surface solar heating over the tropical Indian Ocean, Tellus, 52B, 947-958. 
Ramanathan, V., P. J. Crutzen, J.A. Coakley, A. Clarke, W. D. Collins, R. Dickerson, D. Fahey, B. Gandrud, A. Heymsfield, J. T. Kiehl, J. Kuettner, T. Krishnamurti, D. Lubin, H. Maring, J. Ogren, J. Prospero, P. J. Rasch, D. Savoie, G. Shaw (1996), A. Tuck, F. P. J. Valero, E. L. Woodbridge and G. Zhang, Indian Ocean Experiment (INDOEX), A multi-agency proposal for a field experiment in the Indian Ocean, $C^{A}$ publication $\# 162,83 \mathrm{pp}$, Scripps. Inst. Oceanogr., UCSD. La Jolla, Calif.

Remer, L. A., Y. J. Kaufman, D. Tanré, S. Mattoo, D. A. Chu, J. V. Martins, R.-R. Li, C. Ichoku, R. C. Levy, R. G. Kleidman, T. F. Eck, E. Vermote, B. N. Holben (2005), The MODIS Aerosol Algorithm, Products and Validation, J. Atmos. Sci., 62(4), 947-973. 


\section{Figure Captions}

Figure 1a. Scatterplot showing relation between the atmospheric path transmission and the aerosol optical path at $0.5 \mu \mathrm{m}$ for the interval $30^{\circ}<\theta_{o}<40^{\circ}$. The line is the linear regression, and $n$ is the number of data point. Each point represents measurements of the 1-min mean atmospheric path transmission and the instantaneous aerosol optical path.

Figure 1b. Same as Figure 1a, except for the interval $40^{\circ}<\theta_{o}<50^{\circ}$.

Figure 1c. Same as Figure 1a, except for the interval $50^{\circ}<\theta_{o}<60^{\circ}$.

Figure 1d. Same as Figure 1a, except for the interval $60^{\circ}<\theta_{o}<70^{\circ}$.

Figure 1e. Same as Figure 1a, except for the interval $70^{\circ}<\theta_{o}<80^{\circ}$.

Figure 2. Same as Figure 1a, except data measured at all $\theta_{o}$ are included. 
Table 1. Spectral intervals of the eight bands of the radiation model and the seven spectral channels where the aerosol optical thickness $(\tau)$, single-scattering albedo $\left(\omega_{o}\right)$, and asymmetry factor $(g)$ are retrieved from the Cimel radiation measurements. Units are $\mu \mathrm{m}$.

\begin{tabular}{llll}
\hline Band & Radiation Model & Cimel $\tau$ & Cimel $\omega_{o}, g$ \\
& & & \\
1 & $0.225-0.285$ & & \\
2 & $0.175-0.225$ & & \\
3 & $0.285-0.300$ & & \\
4 & $0.300-0.325$ & & $0.440,0.670$ \\
5 & $0.325-0.400$ & $0.340,0.380$ & $0.870,1.02$ \\
6 & $0.400-0.690$ & $0.440,0.500,0.670$ & \\
7 & $0.690-0.122$ & $0.870,1.02$ & \\
\hline 8 & $0.122-0.227$ & & \\
\hline
\end{tabular}


Table 2. The aerosol optical thickness, $\tau$, single-scattering albedo $\omega_{o}$, asymmetry factor, $g$, at $0.5 \mu \mathrm{m}$ retrieved from Cimel radiance measurements. The symbol \#D denotes the number of days when all the three aerosol parameters are retrieved. The symbol $\Delta$ denotes the range of the aerosol optical properties within a month.

\begin{tabular}{lccccccc}
\hline Month & \#D & $\tau$ & $\Delta \tau$ & $\omega_{o}$ & $\Delta \omega_{o}$ & $g$ & $\Delta g$ \\
\hline Dec 2003 & 9 & 0.52 & $0.38-0.93$ & 0.963 & $0.94-0.98$ & 0.685 & $0.68-0.73$ \\
Jan 2004 & 14 & 0.51 & $0.32-0.81$ & 0.958 & $0.94-0.98$ & 0.700 & $0.69-0.72$ \\
Feb 2004 & 9 & 0.72 & $0.30-0.78$ & 0.946 & $0.92-0.97$ & 0.696 & $0.65-0.73$ \\
Mar 2004 & 19 & 1.18 & $0.31-2.01$ & 0.941 & $0.92-0.96$ & 0.695 & $0.68-0.72$ \\
Mean & & 0.73 & & 0.952 & & 0.694 & \\
\hline
\end{tabular}


Table 3. The mean incoming solar radiation at the top of the atmosphere, $\overline{\mu_{o} S_{o}}$, the downward surface solar radiation measured by PSP, $F_{o b s}{ }^{\text {total }}$, and the atmospheric transmission, $T_{a t m}$, where $\mu_{o}$ is the cosine of the solar zenith angle, and $S_{o}$ is the extraterrestrial solar radiation. Units of fluxes are $\mathrm{W} \mathrm{m}^{-2}$.

\begin{tabular}{lccr}
\hline Month & $\overline{\mu_{o} S_{o}}$ & $F_{\text {obs }}^{\text {total }}$ & $T_{\text {atm }}$ \\
\hline Dec 2003 & 273.7 & 150.2 & 0.549 \\
Jan 2004 & 287.5 & 146.1 & 0.508 \\
Feb 2004 & 336.6 & 163.3 & 0.485 \\
Mar 2004 & 390.2 & 184.6 & 0.473 \\
Mean & 322.0 & 161.0 & 0.500 \\
\hline
\end{tabular}


Table 4. The mean surface radiation of cloud-free skies calculated from a radiation model $(\mathrm{mod})$ and estimated from surface observations $(\mathrm{obs})$ for skies without aerosols $(N A)$ and with aerosols $(W A)$. Units are $\mathrm{Wm}^{-2}$.

\begin{tabular}{ccccc}
\hline Month & $F_{\text {mod }}{ }^{N A}$ & $F_{\text {mod }}{ }^{W A}$ & $F_{\text {obs }}{ }^{N A}$ & $F_{\text {obs }}{ }^{W A}$ \\
\hline Dec 2003 & 203.3 & 176.2 & 186.2 & 162.7 \\
Jan 2004 & 217.3 & 190.8 & 194.0 & 170.2 \\
Feb 2004 & 255.8 & 223.1 & 236.3 & 198.4 \\
Mar 2004 & 295.8 & 234.4 & 280.0 & 209.5 \\
Mean & 243.7 & 206.5 & 224.9 & 185.6 \\
\hline
\end{tabular}


Table 5. The intercept and slope of the linear regression for $10^{\circ} \theta_{o}-$ bins. The solar zenith angle, $\theta_{o}$, in Tainan during the winter months December-March is always $>23^{\circ}$.

\begin{tabular}{ccl}
\hline$\theta_{o}$-bin & Intercept, $\alpha$ & Slope, $\gamma$ \\
\hline $20^{\circ}<\theta_{o}<30^{\circ}$ & $0.750^{\mathrm{a}}$ & $-0.127^{\mathrm{a}}$ \\
$30^{\circ}<\theta_{o}<40^{\circ}$ & 0.740 & -0.115 \\
$40^{\circ}<\theta_{o}<50^{\circ}$ & 0.724 & -0.102 \\
$50^{\circ}<\theta_{o}<60^{\circ}$ & 0.685 & -0.084 \\
$60^{\circ}<\theta_{o}<70^{\circ}$ & 0.633 & -0.075 \\
$70^{\circ}<\theta_{o}<80^{\circ}$ & 0.554 & -0.056 \\
$80^{\circ}<\theta_{o}<90^{\circ}$ & $0.430^{\mathrm{a}}$ & $-0.015^{\mathrm{a}}$ \\
\hline
\end{tabular}

${ }^{\mathrm{a}}$ Approximation from extrapolation. 
Table 6. The aerosol radiative effect (ARE) and aerosol radiative sensitivity (ARS) derived from surface radiation observations and from radiation model calculations. Units are $\mathrm{Wm}^{-2}$.

\begin{tabular}{lcccc}
\hline Month & $\begin{array}{c}\text { ARE } \\
(\text { obs })\end{array}$ & $\begin{array}{c}\text { ARE } \\
(\text { model })\end{array}$ & $\begin{array}{c}\text { ARS } \\
(\text { obs })\end{array}$ & $\begin{array}{c}\text { ARS } \\
(\text { model })\end{array}$ \\
\hline Dec 2003 & -23.5 & -27.1 & -45.2 & -52.1 \\
Jan 2004 & -23.8 & -26.5 & -46.7 & -52.0 \\
Feb 2004 & -37.9 & -32.7 & -52.6 & -45.4 \\
Mar 2004 & -70.6 & -61.4 & -59.8 & -52.0 \\
Mean & -39.0 & -37.0 & -51.0 & -50.5 \\
\hline
\end{tabular}


Table 7. Same as Table 6, except the coefficient $\alpha$ and $\gamma$ used in computing the ARE and ARS are taken from the regression that includes data measured at all $\theta_{o}$. Units are $\mathrm{Wm}^{-2}$.

\begin{tabular}{lll}
\hline & ARE (obs) & ARS (obs) \\
\hline Dec 2003 & -30.6 & -58.8 \\
Jan 2004 & -30.4 & -59.6 \\
Feb 2004 & -44.1 & -61.3 \\
Mar 2004 & -75.9 & -64.3 \\
Mean & -45.3 & -61.0 \\
\hline
\end{tabular}




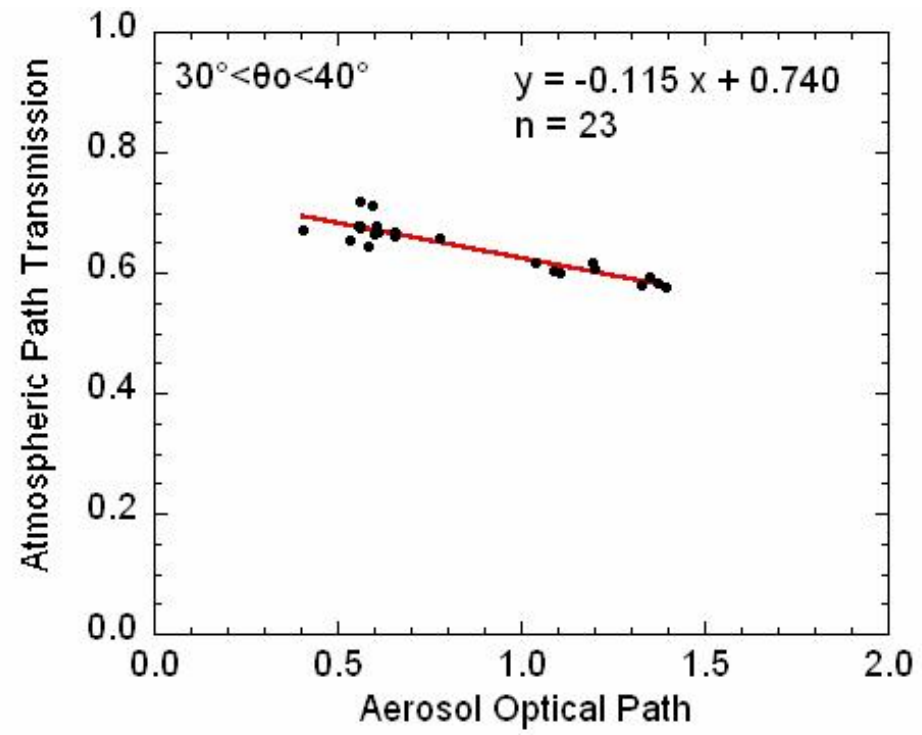

Figure 1a. Scatterplot showing relation between the atmospheric path transmission and the aerosol optical path at $0.5 \mathrm{~mm}$ for the interval $30^{\circ}<\theta 0<40^{\circ}$. The line is the linear regression, and $\mathrm{n}$ is the number of data point. Each point represents measurements of the 1-min mean atmospheric path transmission and the instantaneous aerosol optical path. 


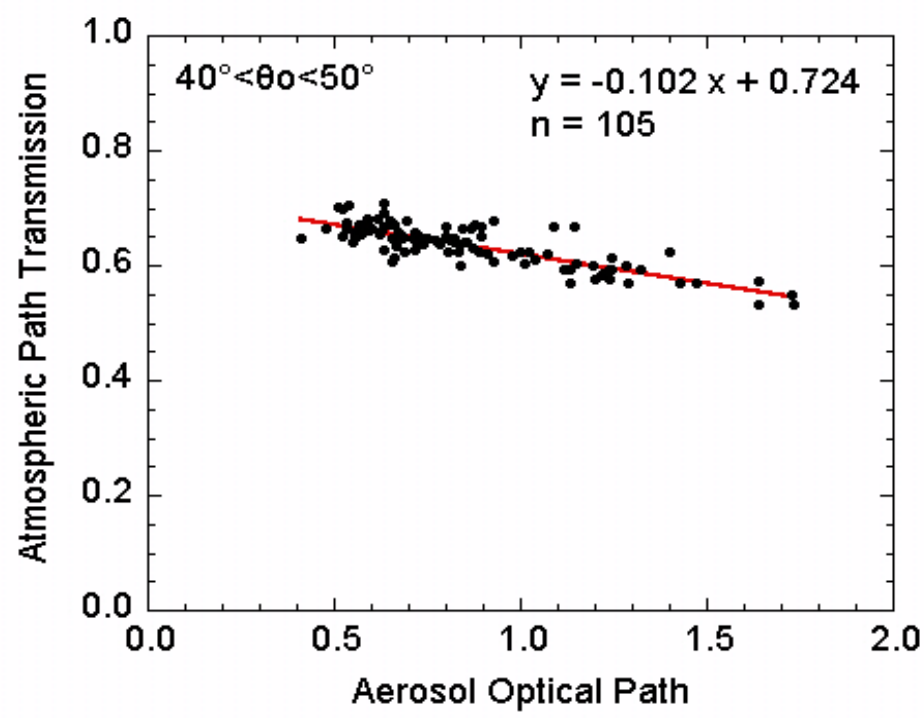

Figure 1b. Same as Figure 1a, except for the interval $40^{\circ}<\theta 0<50^{\circ}$. 


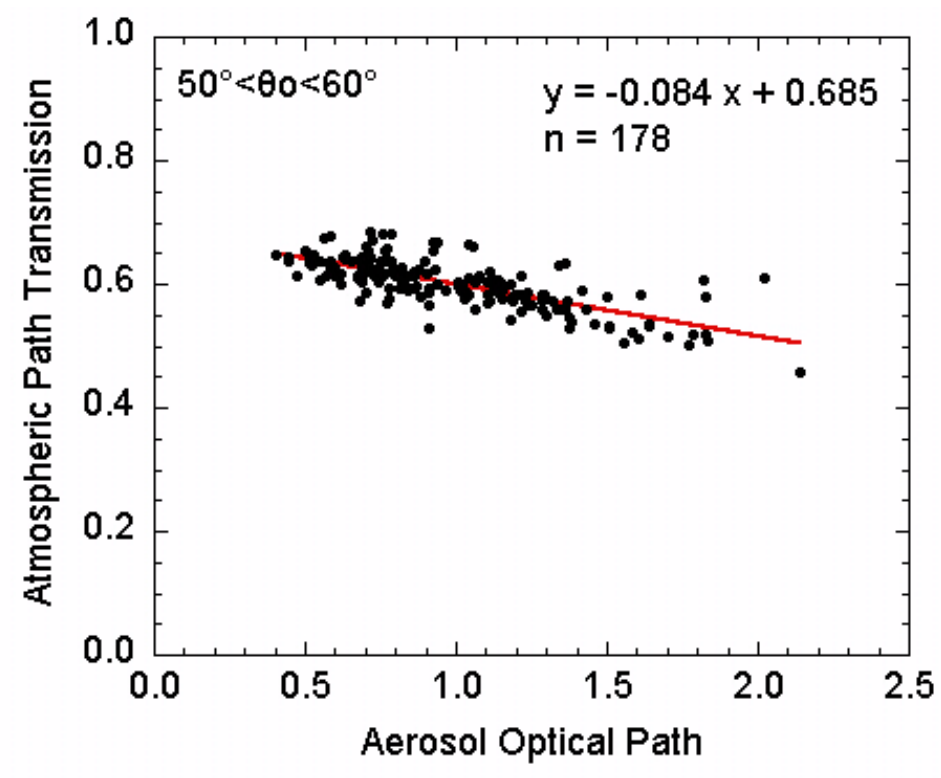

Figure 1c. Same as Figure $1 \mathrm{a}$, except for the interval $50^{\circ}<\theta 0<60^{\circ}$. 


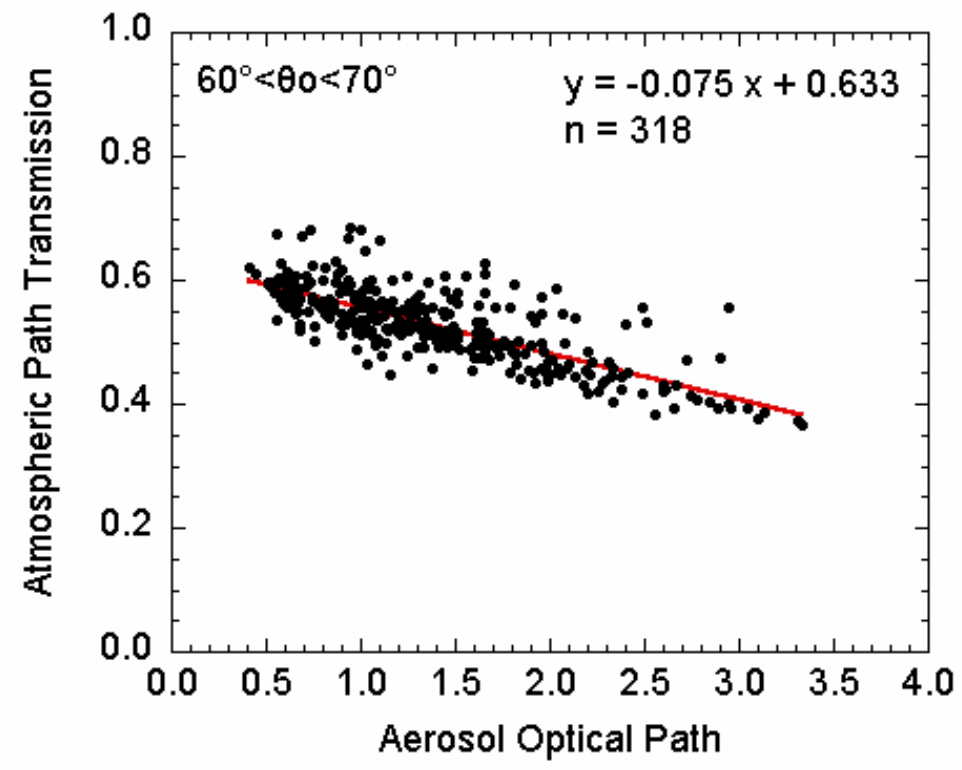

Figure 1d. Same as Figure 1a, except for the interval $60^{\circ}<\theta 0<70^{\circ}$. 


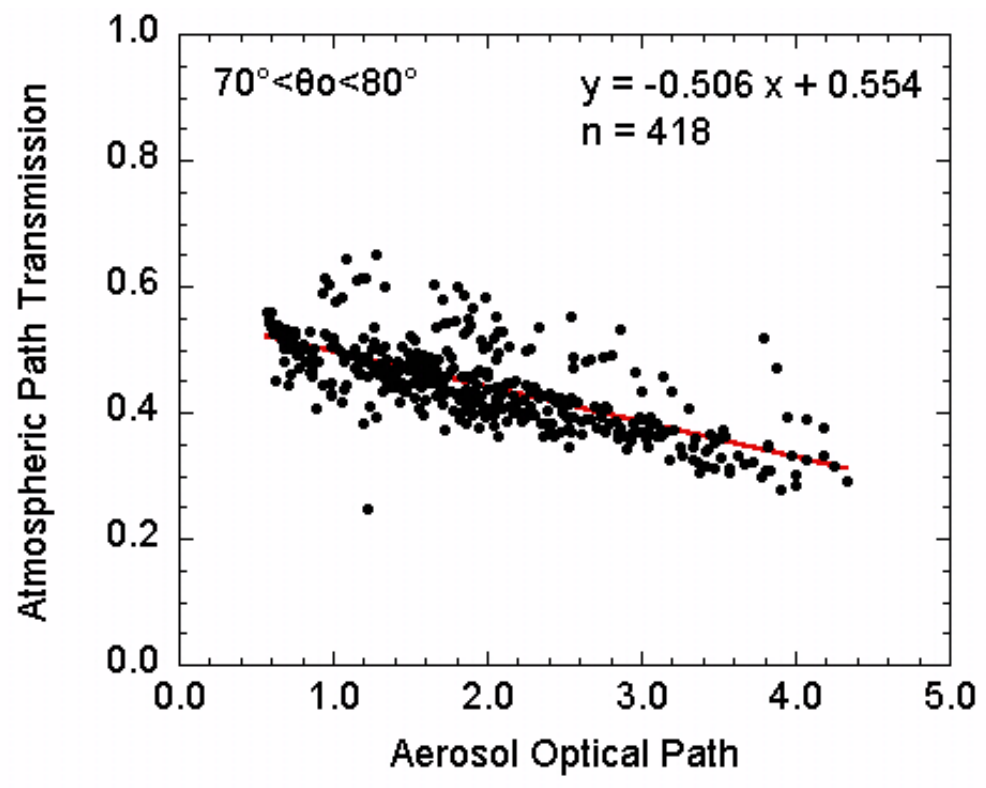

Figure 1e. Same as Figure 1a, except for the interval $70^{\circ}<\theta 0<80^{\circ}$. 


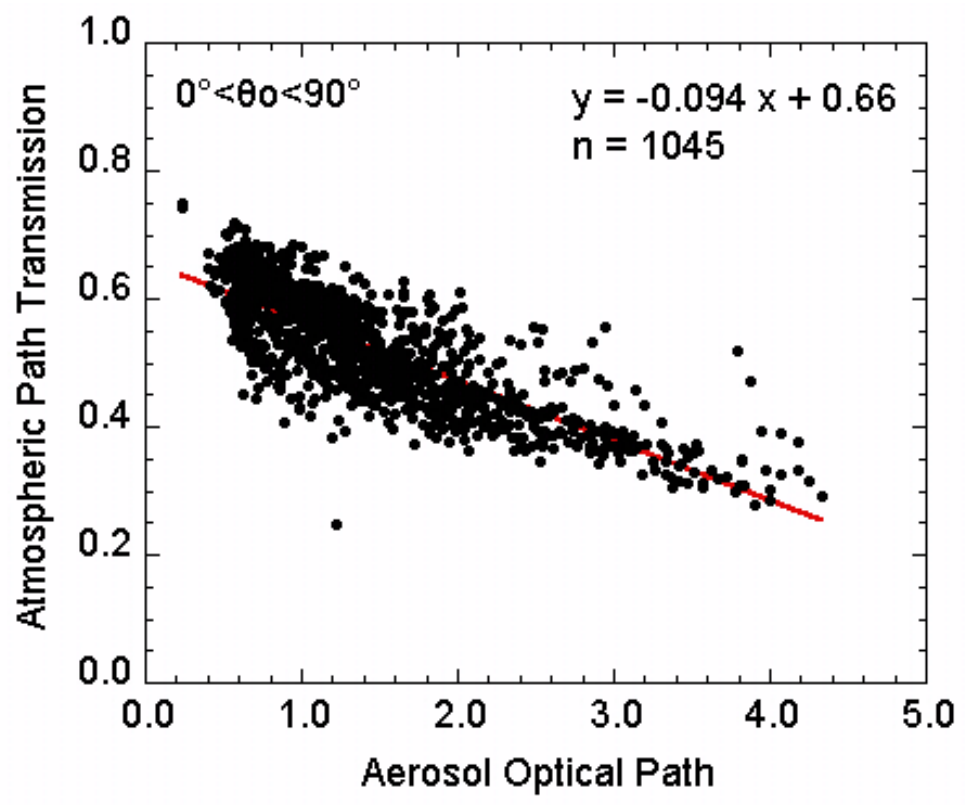

Figure 2. Same as Figure 1a, except data measured at all $\theta 0$ are included. 